\title{
Knockdown of the gene encoding Drosophila tribbles homologue 3 (Trib3) improves insulin sensitivity through peroxisome proliferator-activated receptor- $\gamma$ (PPAR- $\gamma$ ) activation in a rat model of insulin resistance
}

\author{
D. Weismann • D. M. Erion • I. Ignatova-Todorava • Y. Nagai • R. Stark • J. J. Hsiao • \\ C. Flannery • A. L. Birkenfeld • T. May • M. Kahn • D. Zhang • X. X. Yu • \\ S. F. Murray • S. Bhanot • B. P. Monia • G. W. Cline • G. I. Shulman • V. T. Samuel
}

Received: 5 June 2010 / Accepted: 20 October 2010 / Published online: 29 December 2010

(C) Springer-Verlag (outside the USA) 2010

\begin{abstract}
Aims/hypothesis Insulin action is purportedly modulated by Drosophila tribbles homologue 3 (TRIB3), which in vitro prevents thymoma viral proto-oncogene (AKT) and peroxisome proliferator-activated receptor- $\gamma$ (PPAR- $\gamma$ ) activation. However, the physiological impact of TRIB3 action in vivo remains controversial.

Methods We investigated the role of TRIB3 in rats treated with either a control or Trib3 antisense oligonucleotide (ASO). Tissue-specific insulin sensitivity was assessed in vivo using a euglycaemic-hyperinsulinaemic clamp. A separate group was treated with the PPAR- $\gamma$ antagonist bisphenol-A-diglycidyl ether (BADGE) to assess the role of PPAR- $\gamma$ in mediating the response to Trib3 ASO.
\end{abstract}

Electronic supplementary material The online version of this article (doi:10.1007/s00125-010-1984-5) contains supplementary material, which is available to authorised users.

D. Weismann · D. M. Erion · I. Ignatova-Todorava $\cdot$ Y. Nagai $\cdot$

R. Stark $\cdot$ J. J. Hsiao $\cdot$ C. Flannery $\cdot$ A. L. Birkenfeld $\cdot$

G. W. Cline $\cdot$ G. I. Shulman $\cdot$ V. T. Samuel $(\bowtie)$

Section of Endocrinology, Department of Internal Medicine,

Yale University School of Medicine,

PO Box 802010, New Haven, CT 06520-8020, USA

e-mail: varman.samuel@yale.edu

D. M. Erion • G. I. Shulman

Department of Cellular and Molecular Physiology,

Yale University School of Medicine,

New Haven, CT, USA

D. M. Erion $\cdot$ T. May $\cdot$ M. Kahn $\cdot$ D. Zhang $\cdot$ G. I. Shulman

Howard Hughes Medical Institute,

Yale University School of Medicine,

New Haven, CT, USA
Results Trib3 ASO treatment specifically reduced Trib3 expression by $70 \%$ to $80 \%$ in liver and white adipose tissue. Fasting plasma glucose, insulin concentrations and basal rate of endogenous glucose production were unchanged. However, Trib3 ASO increased insulin-stimulated whole-body glucose uptake by $\sim 50 \%$ during the euglycaemic-hyperinsulinaemic clamp. This was attributable to improved skeletal muscle glucose uptake. Despite the reduction of Trib3 expression, AKT2 activity was not increased. Trib3 ASO increased white adipose tissue mass by $70 \%$ and expression of Ppar- $\gamma$ and its key target genes, raising the possibility that Trib3 ASO improves insulin sensitivity primarily in a PPAR- $\gamma$-dependent manner. Co-treatment with BADGE blunted the expansion of white adipose tissue and abrogated the insulin-sensitising effects of Trib3 ASO.

V. T. Samuel
Veterans Affairs Medical Center,
West Haven, CT, USA

X. X. Yu - S. F. Murray · S. Bhanot - B. P. Monia Isis Pharmaceuticals,

Carlsbad, CA, USA

D. Weismann

Universitätsklinikum Würzburg,

Medizinische Klinik und Poliklinik I,

Schwerpunkt Endokrinologie und Diabetologie,

Würzburg, Germany 
Finally, Trib3 ASO also increased plasma HDL-cholesterol, a change that persisted with BADGE co-treatment.

Conclusions/interpretation These data suggest that TRIB3 inhibition improves insulin sensitivity in vivo primarily in a PPAR- $\gamma$-dependent manner and without any change in AKT2 activity.

Keywords Antisense oligonucleotide. Euglycaemic-hyperinsulinaemic clamp . Insulin sensitivity · PPAR gamma $\cdot$ TRIB3

$\begin{array}{ll}\text { Abbreviations } \\ \text { ACO } & \text { Acyl-CoA oxidase } \\ \text { AKT } & \text { Thymoma viral proto-oncogene } \\ \text { AMPK } & \text { AMP-activated protein kinase } \\ \text { ASO } & \text { Antisense oligonucleotide } \\ \text { BADGE } & \text { Bisphenol-A-diglycidyl ether } \\ \text { CEBP } & \text { CCAAT/enhancer binding protein } \\ \text { FPLC } & \text { Fast protein liquid chromatography } \\ \text { PPAR } & \text { Peroxisome proliferator-activated receptor } \\ \text { TRIB } & \text { Drosophila tribbles homologue }\end{array}$

\section{Introduction}

Insulin signalling in muscle and liver share common pathways that converge on key kinases, such as serine/ threonine kinase AKT2. In liver, insulin-mediated AKT2 activation regulates hepatic glucose production by promoting glycogen synthesis and inhibiting gluconeogenesis [1]. AKT2 activation is an essential step for insulin-induced GLUT4 translocation in skeletal muscle, promoting glucose uptake [1-3]. In the pathogenesis of insulin resistance, accumulation of diacylglycerol in muscle and liver leads to activation of novel protein kinase Cs ( $\theta$ and $\varepsilon$, respectively) that inhibit insulin signalling and impair activation of AKT2 [1, 4, 5]. However, cells also possess inherent mechanisms to negatively regulate insulin signalling. Recently, the Drosophila tribbles homologue 3 (TRIB3) was identified as a negative regulator of AKT activity in human embryonic kidney 293 cells and mouse liver [6]. Fasting induces hepatic TRIB3 production and TRIB3 is highly upregulated in diabetic $d b / d b$ mice [7]. TRIB3 production is also increased in other experimental conditions associated with insulin resistance, such as highfructose feeding [8] or chronic ethanol consumption [9]. Insulin may also cause increased TRIB3 production, suggesting a possible pathway whereby hyperinsulinaemia could lead to impaired insulin signalling [10].

TRIB3 has been implicated in insulin resistance in humans. Liu et al. reported that TRIB3 protein levels are significantly elevated in patients with type 2 diabetes mellitus [11]. In that cohort, higher levels of TRIB3 protein were associated with hyperglycaemia and reduced insulinstimulated whole-body glucose disposal, suggesting that TRIB3 content was closely associated with the development of insulin resistance [11]. Aside from changes in abundance, polymorphisms that affect the function of TRIB3 have also been implicated in the development of insulin resistance and type 2 diabetes mellitus in humans. Specifically, the Q84R missense polymorphism has been associated with worsening insulin resistance and dyslipidaemia [12, 13]. Prudente et al. found an association between this polymorphism and some features of the metabolic syndrome [12]. In a larger analysis, they also reported an association between the Q84R polymorphism and an increased risk of type 2 diabetes mellitus, especially among individuals who are 45 years of age or younger [14]. Andreozzi et al. suggested that this polymorphism may also lead to endothelial dysfunction [15]. Using human umbilical vein endothelial cells isolated from individuals who were either heterozygous or homozygous for the R84 (i.e. QR or RR) polymorphism, they demonstrated that the R84 polymorphism impaired insulin-mediated increases in endothelial nitric oxide synthase activity. This substitution of arginine for glutamine at position 84 is thought to enhance the ability of TRIB3 to impede AKT2 activation [12] possibly by enhancing the binding between TRIB3 and AKT2 [15]. Together, these studies suggest that increases in TRIB3 activity are closely associated with insulin resistance and type 2 diabetes mellitus, primarily via inhibition of AKT2 activation.

However, this conclusion is still controversial. Iynedjian reported that overproduction of TRIB3 in hepatocytes had no effect on insulin signalling [16] and Okamoto et al. reported that deletion of Trib3 in mice did not alter insulinstimulated glucose metabolism [17]. Moreover, TRIB3 has been implicated in the regulation of other proteins. In beta cells, TRIB3 may bind with activating transcription factor 4 (ATF4) to inhibit cAMP responsive element binding protein 1 (CREB1)-mediated production of proteins critical to exocytosis of insulin-containing granules (potentially accounting for the decrease in insulin secretion seen in humans with the Q84R polymorphism) [14, 18]. In adipocytes, TRIB3 has been reported to interact with peroxisome proliferatoractivated receptor- $\gamma$ (PPAR- $\gamma$ ) in vitro. TRIB3 suppresses adipocyte differentiation by negatively regulating PPAR- $\gamma$ transcriptional activity, while knockdown of TRIB3 in 3T3L1 cells promotes adipocyte differentiation [19].

Here, we sought to clarify the physiological role of TRIB3 and investigate its potential as a therapeutic target in a rat model of type 2 diabetes mellitus, using antisense oligonucleotides (ASOs) to specifically decrease Trib3 expression. Following treatment, changes in liver, muscle and adipose insulin action were assessed by euglycaemichyperinsulinaemic clamps in awake rats. 


\section{Methods}

Animals All procedures were approved by the Institutional Animal Care and Use Committee of the Yale University School of Medicine. Male Sprague-Dawley rats ( $150 \mathrm{~g})$ were received from Charles River Laboratories (Wilmington, MA, USA) and given 3 days to acclimatise. Rats were then given a $100 \mathrm{mg} / \mathrm{kg}$ dose of nicotinamide by i.p. injection and $15 \mathrm{~min}$ later received a $65 \mathrm{mg} / \mathrm{kg}$ dose of streptozotocin. Rats had a 4 day recovery period prior to the first ASO injection. Rats were housed individually on a $12 \mathrm{~h}$ light-dark cycle, with free access to food and water. Body weight and food consumption were monitored weekly. Animals were fed a high-fat diet (energy intake $26 \%$ carbohydrate, $59 \%$ fat, $15 \%$ protein), in which the major constituent was safflower oil. While on highfat diet, rats were treated with ASO $(75 \mathrm{mg} / \mathrm{kg}$ per week, given twice weekly i.p.). This model has previously been shown to prevent the hyperinsulinaemia seen with high-fat feeding alone [20] and has also been associated with muscle and liver insulin resistance [21].

Selection of rat Trib3 ASO To identify rat Trib3 ASOs, rapid-throughput screens were performed in vitro as previously described [22]. In brief, 80 ASOs were designed to the Trib3 mRNA sequence. Initial screens identified several potent and specific ASOs, all of which targeted a binding site within the coding region of Trib3 mRNA. After extensive dose-response characterisation, the most potent ASO from the screen was chosen. It was ISIS-391274, and had the following sequence: 5'-GTCCAGTCATCACA CAGGCA-3'. The control ASO, ISIS-141923, has the sequence 5'-CCTTCCCTGAAGGTTCCTCC-3' and does not have perfect complementarity to any known gene in public databases. The first five bases and last five bases of chimeric ASOs have a 2'-O-(2-methoxy)-ethyl modification; the ASOs also have a phosphorothioate backbone. This chimeric design has been shown to provide increased nuclease resistance and mRNA affinity, while maintaining the robust RNase $\mathrm{H}$ terminating mechanism used by these types of ASOs [23]. These benefits result in an attractive in vivo pharmacological and toxicological profile for $2^{\prime}-O$ (2-methoxy)-ethyl chimeric ASOs [24].

Co-administration of the PPAR- $\gamma$ antagonist bisphenol-Adiglycidyl ether Rats had unrestricted access to a $27 \%$ (wt/wt) high-fat diet and were treated with Trib3 or control ASO as described above. For the last 8 days of ASO treatment, the PPAR- $\gamma$ antagonist bisphenol-A-diglycidyl ether (BADGE) (Cayman Chemical, Ann Arbor, MI, USA) was subcutaneously injected once daily (1 mg/kg body weight) [25].

Euglycaemic-hyperinsulinaemic clamp studies At 7 to 9 days prior to the euglycaemic-hyperinsulinaemic clamp, catheters were inserted into the right internal jugular vein extending to the right atrium and the left carotid artery extending into the aortic arch. Subsequently the rats were fasted overnight (from 18.00 hours) and on the following morning (06.00 hours) were infused with $\left[6,6{ }^{2} \mathrm{H}\right]$ glucose (99\% enriched, $6.1 \mathrm{nmol} / \mathrm{kg}$ prime, $0.5 \mathrm{nmol} / \mathrm{kg}$ ) infusion to assess basal glucose turnover. After the basal period, the euglycaemic-hyperinsulinaemic clamp was conducted for $140 \mathrm{~min}$ with a primed/continuous infusion of insulin ( $400 \mathrm{mU} / \mathrm{kg}$ prime over $5 \mathrm{~min}$, thereafter $4 \mathrm{mU} / \mathrm{kg}$ per $\mathrm{min}$ ) and a variable infusion of $20 \%$ (wt./vol.) dextrose enriched with $2.5 \%\left[6,6-{ }^{2} \mathrm{H}\right]$ glucose to maintain euglycaemia. At 0 and $140 \mathrm{~min}$ additional blood was drawn to determine various blood proteins and metabolites. Upon completion of the clamp, rats were anaesthetised with pentobarbital sodium injection $(150 \mathrm{mg} / \mathrm{kg})$ and all tissues were extracted and frozen immediately using liquid $\mathrm{N}_{2}$-cooled aluminium tongs. Tissues were stored at $-80^{\circ} \mathrm{C}$ for subsequent analysis.

Liver insulin signalling A separate group of rats that were treated exactly the same as the previous were used to investigate the effect of TRIB3 treatment on insulin signalling. These rats underwent a $20 \mathrm{~min}$ euglycaemichyperinsulinaemic clamp. Immediately after the clamp, rats were killed and the liver removed and subsequently frozen using liquid $\mathrm{N}_{2}$-cooled brass tongs. The activity of AKT was assessed by measuring the incorporation of ${ }^{32} \mathrm{P}$ into a synthetic AKT substrate as previously described [26].

Biochemical analysis and calculations Plasma glucose was determined during the clamp using $10 \mu \mathrm{l}$ plasma and the glucose oxidase method performed by an analyser (Beckman Glucose Analyzer II; Beckman Coulter, Brea, CA, USA). Plasma insulin, glucagon, leptin and adiponectin concentrations were determined using an assay system (Lincoplex; Linco Research, St Charles, MO, USA). For fast protein liquid chromatography (FPLC) analysis, samples from control ASO and Trib3 ASO were pooled, injected on to an AKTa FPLC (Amersham Pharmacia Biotech, Piscataway, NJ, USA) and eluted at a constant flow rate of $0.5 \mathrm{ml} / \mathrm{min}$ FPLC buffer ( $0.15 \mathrm{~mol} / 1 \mathrm{NaCl}, 0.01 \mathrm{~mol} / 1 \mathrm{Na}_{2} \mathrm{HPO}_{4}, 0.1 \mathrm{mmol} / \mathrm{l}$ EDTA, $\mathrm{pH}$ 7.5). To determine the enrichment of plasma glucose, $30 \mu \mathrm{l}$ of the designated samples were deproteinised in $150 \mu \mathrm{l}$ $100 \%$ methanol. The samples were dried overnight and derivatised with 1:2 acetic anhydride:pyridine to produce the pentaacetate derivative of glucose. The atom percentage enrichment of $\left[6,6-{ }^{2} \mathrm{H}\right]$ glucose was then measured by gas chromatographic/mass spectrometric analysis using a gas chromatograph (Hewlett-Packard 5890; GMI, Ramsey, MN, USA) interfaced to a mass-selective detector (HewlettPackard 5971A) operating in the electron ionisation mode [27]. The atom per cent excess of glucose $\mathrm{M}_{\mathrm{M}+2}$ was determined from the $m: z$ ratio 202:200. 
Tissue lipid measurement The purification of diacylglycerol from liver was performed as previously described [28, 29]. After purification, fatty acyl-CoA fractions were dissolved in methanol: $\mathrm{H}_{2} \mathrm{O}(1: 1$, vol./vol.) and subjected to liquid chromatography-tandem mass spectrometry. A turbo ion spray source was interfaced with a tandem mass spectrometer (API 3000; Applied Biosystems, Carlsbad, CA, USA) in conjunction with two micro pumps and an autosampler (200 Series; PerkinElmer, Waltham, MA, USA). Total diacylglycerol content is expressed as the sum of individual species. Triacylglycerol was extracted using the method of Bligh and Dyer [29] and measured with a commercially available kit (DCL Triglyceride Reagent; Diagnostic Chemicals, Oxford, CT, USA).

Total RNA preparation and real-time quantitative RT-PCR analysis Total RNA was extracted from liver samples using a kit (RNeasy; Qiagen, Valencia, CA, USA). RNA was reverse-transcribed into cDNA with reverse transcriptase (StrataScript; Stratagene, Santa Clara, CA, USA). The abundance of transcripts was assessed by real-time PCR (7500 Fast Real-Time PCR System; Applied Biosystems) with SYBR Green detection system (Stratagene). For each run, samples were run in duplicate for the gene of interest and $\beta$-actin. The expression data for each gene of interest and $\beta$-actin were normalised for the efficiency of amplification, as determined by a standard curve included on each run [30].

Immunoblots White adipose tissue, liver and muscle specimens were ground with a mortar and pestle, mixed with $1 \mathrm{ml}$ of lysis buffer $(50 \mathrm{mmol} / 1$ Tris- $\mathrm{HCl}$ buffer $[\mathrm{pH} 7.5$ at $4^{\circ} \mathrm{C}$ ], $50 \mathrm{mmol} / \mathrm{l} \mathrm{NaF}, 5 \mathrm{mmol} / \mathrm{l} \mathrm{NaPPi}, 1 \mathrm{mmol} / \mathrm{l}$ EDTA, $1 \mathrm{mmol} / 1 \mathrm{EGTA}, 1 \mathrm{mmol} / 1$ dithiothreitol, $1 \mathrm{mmol} / 1$ benzamidine, $1 \mathrm{mmol} / \mathrm{l}$ phenylmethanesulfonyl fluoride, glycerol [10\% vol./vol.], Triton X-100 [1\% vol./vol.], $1 \mu \mathrm{mol} / 1$ trichostatin $\mathrm{A}$ and $50 \mathrm{mmol} / \mathrm{l}$ nicotinamide) and homogenised for $30 \mathrm{~s}$. Homogenates were spun at 20,800 $\mathrm{g}$ for $10 \mathrm{~min}$ at $4^{\circ} \mathrm{C}$ and protein concentrations were determined. SDS gel electrophoresis was performed using precast BisTris 4 to $12 \%$ gradient polyacrylamide gels in the Mops buffer system (Invitrogen, CA, USA). After transfer to nitrocellulose membranes, membranes were incubated in blocking buffer (5\% [wt/vol.] milk) for $1 \mathrm{~h}$ and immunoblotted with TRIB3 (Santa Cruz, Heidelberg, Germany), $\beta$-actin (Santa Cruz), phospho-AKT (Cell Signaling Technology, MA, USA) and AKT (Cell Signaling Technology) antibodies. After incubation with the primary antibody, the membranes were washed three times for 15 min with Trisbuffered saline $(10 \mathrm{mmol} / 1 \mathrm{Tris}-\mathrm{HCl}[\mathrm{pH} 7.4], 0.5 \mathrm{~mol} / \mathrm{l} \mathrm{NaCl})$ plus Tween $20(0.2 \%$ vol./vol. $)$ (TBST). The membranes were immersed in blocking buffer and a corresponding IgGconjugated secondary antibody, and incubated for $2 \mathrm{~h}$. The membranes were then washed three times for 5 min using
TBST. Proteins were then detected with enhanced chemiluminescence (Thermo Fisher Scientific, Waltham, MA, USA) and autoradiographs were quantified by densitometry (ImageJ).

Statistical analysis All values are expressed as the mean \pm SEM. The significance between the mean values was evaluated by two-tailed unpaired Student's $t$ test. Significance is indicated as ${ }^{*} p<0.05,{ }^{* *} p<0.01$ and ${ }^{* * *} p<0.001$. Statistical analysis was performed with the statistical software R [31].

\section{Results}

Trib3 ASO is specific and effective Trib3 ASO treatment specifically reduced Trib3 expression in liver (by 70\%) and epididymal white adipose tissue (by $80 \%$ ) after 4 weeks of treatment at $75 \mathrm{mg} / \mathrm{kg}$ per week. No significant differences were seen for Trib1 and Trib2 expression in liver or white adipose tissue (Fig. 1a-d). Body weight and food intake were similar in both groups. No differences were seen in fasting plasma glucose, insulin and glucagon levels, or in alanine transferase and aspartate transferase plasma concentrations (Table 1). Surprisingly, epididymal white adipose tissue mass increased by $70 \%$ following Trib3 ASO treatment (Table 1). This was associated with a $25 \%$ increase in plasma adiponectin concentrations, but without any differences in plasma leptin concentration (Table 1).

Trib3 ASO increases peripheral insulin sensitivity We quantified the effects of reduced Trib3 expression on hepatic and peripheral insulin sensitivity using euglycaemic-hyperinsulinaemic clamps in awake, unrestrained rats ( $n=12$ per group) [4]. Trib3 ASO did not affect rates of endogenous glucose production either under basal or euglycaemic-hyperinsulinaemic conditions (Fig. 2a, c). However, under euglycaemic-hyperinsulinaemic conditions, Trib3 ASO did increase the rate of whole-body glucose uptake by $47 \%$ (Fig. 2d). This increase in insulin-stimulated peripheral glucose disposal was largely accounted for by improved skeletal muscle glucose uptake. Peripheral 2-deoxy $\left[{ }^{14} \mathrm{C}\right]$ glucose uptake was $30 \%$ and $40 \%$ higher in tibialis anterior and soleus muscle (Fig. 3b, f). Although 2-deoxy $\left[{ }^{14} \mathrm{C}\right]$ glucose uptake in epididymal white adipose tissue, assessed on a per gram basis, was not significantly altered with Trib3 ASO ( $1.1 \pm 0.12$ vs $0.87 \pm 0.13$, NS; see Electronic supplementary material [ESM] Fig. 1a, b), the increased adipose tissue mass also contributes to the increase in whole-body insulin-stimulated glucose uptake. In addition, Trib3 ASO modestly enhanced the ability of insulin to suppress plasma NEFA concentration (Table 1).

Trib3 ASO increases PPAR- $\gamma$ activity in epididymal white adipose tissue To determine the cause of increased adipose 
Fig. 1 Trib3 knockdown and interaction with PPAR- $\gamma$. Expression of Trib1, -2 and -3 after 4 weeks of Trib3 ASO treatment (white bars; control ASO, grey bars) in liver (a) and white adipose tissue (d). TRIB3 protein levels in liver (b, c), and (e) expression of Pparg, Cebpb and PPAR- $\gamma$-regulated genes in white adipose tissue. $\mathbf{f}$ Effect of additional BADGE administration after Trib3 ASO treatment on Pparg and PPAR- $\gamma$-regulated genes in white adipose tissue. Values are given as mean \pm SE. $* * p<0.01$ and $* * * p<0.001$, ${ }^{\dagger} p=0.15,{ }^{\ddagger} p=0.05$

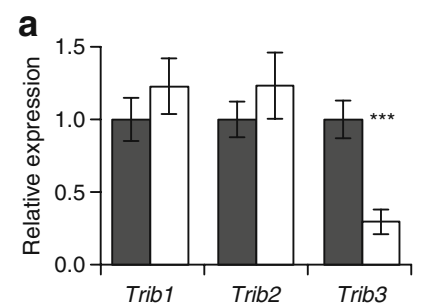

b

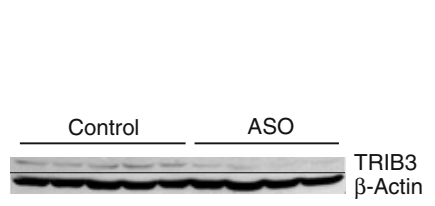

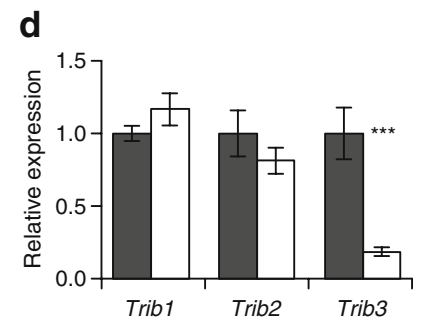

tissue mass, we measured expression of Pparg and downstream targets. Pparg expression was increased by $87 \%$ in the white adipose tissue of Trib3 ASO-treated animals. Consistent with increased PPAR- $\gamma$ activity, the expression of downstream genes such as CCAAT/enhancer binding protein alpha (Cebpa), Cd36 and acyl-CoA oxidase (Acoxl) $[19,25]$ was also increased (Fig. 1e). To assess the specific role of PPAR- $\gamma$ activation following Trib3 ASO treatment, an additional set of animals was treated with the
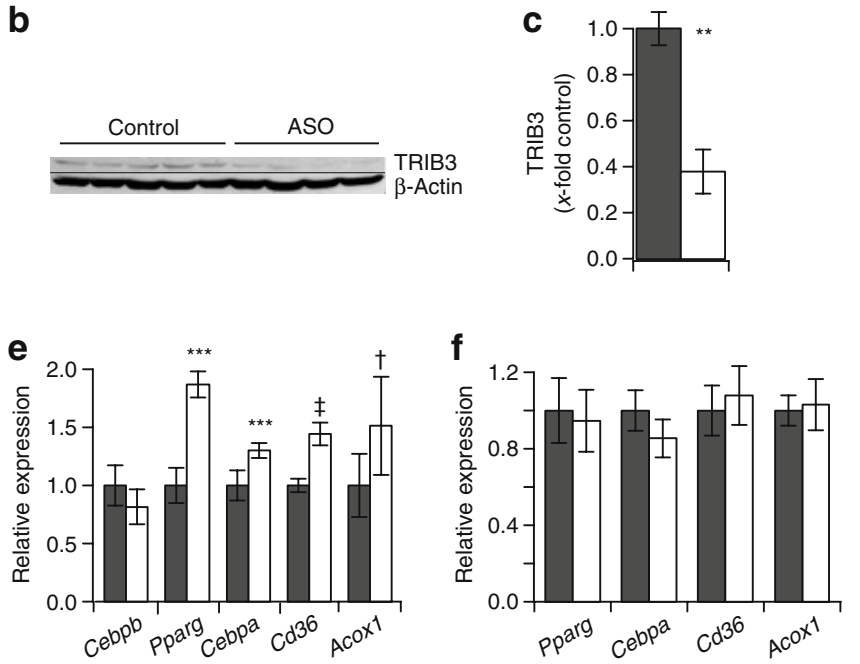

PPAR- $\gamma$ antagonist BADGE for the last 8 days of ASO administration [25]. Again, Trib3 ASO significantly decreased Trib3 levels in liver and white adipose tissue. Body weight and food intake remained similar in animals treated with BADGE+Trib3 ASO and BADGE+control ASO. However, BADGE co-treatment prevented the increased expression of Pparg and of its downstream targets, Cebpa, Cd36 and Acoxl (Fig. 1f). Moreover, in contrast to Trib3 ASO treatment alone, co-treatment with BADGE

Table 1 Biochemical and morphometric data

\begin{tabular}{|c|c|c|c|c|c|c|}
\hline \multirow[t]{2}{*}{ Variable } & \multicolumn{3}{|c|}{ Treatment alone } & \multicolumn{3}{|c|}{ BADGE co-treatment } \\
\hline & Control ASO & Trib3 ASO & Significance & Control ASO & Trib3 ASO & Significance \\
\hline Body weight (g) & $357.9 \pm 8$ & $349.4 \pm 6$ & & $361.4 \pm 6$ & $355 \pm 12$ & \\
\hline White adipose tissue $(\mathrm{g})$ & $3.0 \pm 0.2$ & $5.2 \pm 0.4$ & $* *$ & $4.0 \pm 0.3$ & $4.0 \pm 0.4$ & \\
\hline Leptin $(\mu \mathrm{g} / \mathrm{l})$ & $1.6 \pm 0.2$ & $2.7 \pm 0.6$ & & $1.8 \pm 0.4$ & $1.9 \pm 0.3$ & \\
\hline Adiponectin (mg/l) & $2.4 \pm 0.2$ & $2.9 \pm 0.1$ & $*$ & $2 \pm 0.3$ & $2.4 \pm 0.8$ & \\
\hline IL-6 (ng/l) & $35.9 \pm 9$ & $23.3 \pm 9$ & & $161 \pm 56$ & $260 \pm 63$ & \\
\hline $\mathrm{TNF}-\alpha(\mathrm{ng} / \mathrm{l})$ & $2.9 \pm 0.6$ & $2.7 \pm 0.3$ & & $7.7 \pm 2$ & $16 \pm 5$ & \\
\hline Insulin (pmol/1) & $111 \pm 28$ & $118 \pm 35$ & & $250 \pm 21$ & $118 \pm 21$ & $* * *$ \\
\hline Glucagon (ng/l) & $47.6 \pm 3$ & $53 \pm 6$ & & ND & ND & \\
\hline Glucose (mmol/l) & $6.9 \pm 0.1$ & $7.4 \pm 0.3$ & & $5.7 \pm 0.2$ & $5.9 \pm 0.2$ & \\
\hline $\operatorname{ALT}(\mathrm{U} / \mathrm{l})$ & $44 \pm 6$ & $57 \pm 9$ & & ND & ND & \\
\hline AST (U/1) & $146 \pm 28$ & $192 \pm 33$ & & ND & ND & \\
\hline Cholesterol (mmol/l) & $1.5 \pm 0.1$ & $2.13 \pm 0.2$ & $*$ & $1.5 \pm 0.1$ & $2 \pm 0.2$ & \\
\hline HDL-cholesterol (mmol/l) & $0.6 \pm 0.05$ & $0.9 \pm 0.1$ & $*$ & $0.5 \pm 0.05$ & $0.7 \pm 0.05$ & 0.05 \\
\hline NEFA (mEq/l) & $0.7 \pm 0.04$ & $0.8 \pm 0.07$ & & $0.45 \pm 0.07$ & $0.4 \pm 0.05$ & \\
\hline NEFA suppression (mEq/l) & $-0.45 \pm 0.05$ & $-0.69 \pm 0.06$ & $*$ & ND & ND & \\
\hline Plasma triacylglycerol (mmol/l) & $0.28 \pm 0.03$ & $0.31 \pm 0.02$ & & $0.6 \pm 0.03$ & $0.6 \pm 0.7$ & \\
\hline
\end{tabular}

Data are presented as mean \pm SEM

${ }^{*} p<0.05,{ }^{*} p<0.01$ and ${ }^{* * *} p<0.001$ compared with control ASO

ALT, alanine transferase; AST, aspartate transferase; $\mathrm{mEq}$, milliequivalent; ND, not determined 


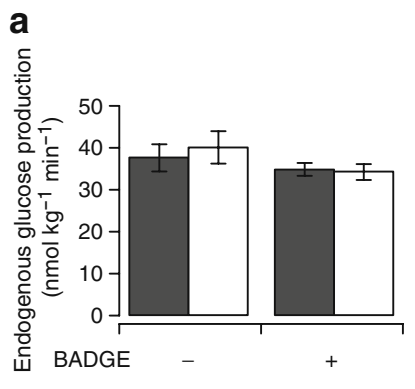

b

C
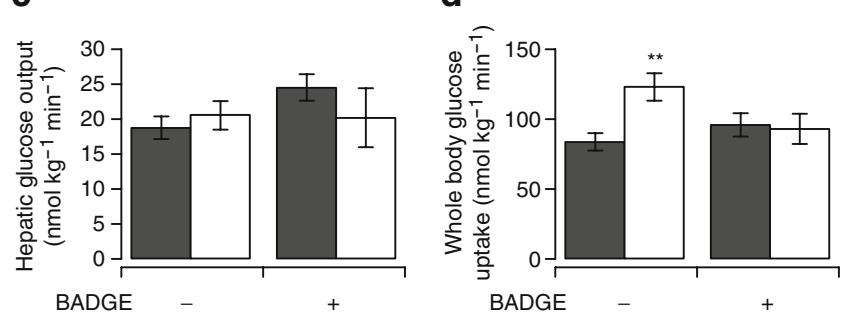

Fig. 2 Glucose turnover assessed by euglycaemic-hyperinsulinaemic clamps. a Endogenous glucose production, (b) glucose infusion rate, (c) insulin-stimulated hepatic glucose output and (d) whole-body glucose turnover in Trib3 ASO-treated (white bars; control ASO, grey bars) animals with and without additional BADGE treatment. Values are given as mean $\pm \mathrm{SE}, n=12$ per group, $n=6-8$ per group for BADGE-treated animals. ${ }^{* *} p<0.01$

prevented the expansion of adipose tissue (Table 1). The increased insulin sensitivity during the euglycaemichyperinsulinaemic portion of the clamp was also completely abolished after BADGE treatment, with no differences in whole-body glucose disposal or hepatic glucose production (Fig. 2b-d). a

d

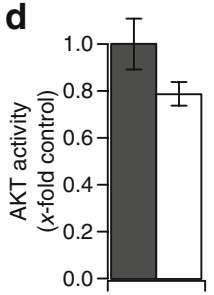

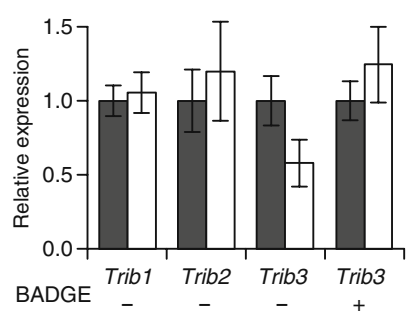

b

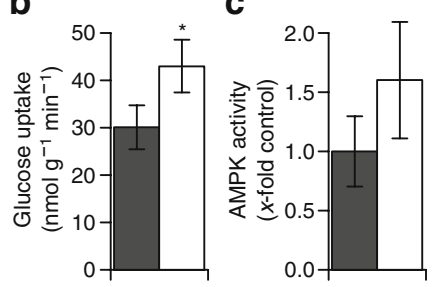

Fig. 3 Glucose uptake and Trib3 expression in muscle. a Expression of Trib1, -2, -3 and Trib3 with BADGE in soleus muscle. b Glucose uptake and (c) AMPK activity in soleus muscle. d AKT2 activity, (e) triacylglycerol content and (f) glucose uptake in tibialis anterior muscle. Values are given as mean $\pm \mathrm{SE}, n=8$ per group. ${ }^{*} p<0.05$. White bars, Trib3 ASO; grey bars, control ASO
Trib3 ASO increases HDL-cholesterol Although plasma triacylglycerol and fatty acid concentrations were similar in both groups, we observed a $40 \%$ increase in plasma total cholesterol concentration in Trib3 ASO-treated animals (Table 1). This increase was accounted for by a $50 \%$ increase in the HDL fraction, as confirmed by FPLC-based size separation of lipoproteins. The increase in plasma HDL-cholesterol was associated with increased levels of sterol regulatory element binding factor 2 (Srebp2) but without any change in scavenger receptor class B, member 1 (Sr-b1 [also known as Scarb1]) or ATP-binding cassette, sub-family A, member 1 (Abcal). Importantly, increased HDL-cholesterol levels were also observed after BADGE treatment, indicating that these effects were independent of PPAR- $\gamma$ activation (Table 1).

Insulin signalling TRIB3 has been shown to inhibit activation of AKT and by extension insulin signalling in vitro. Thus, we hypothesised that knockdown of Trib3 would increase AKT2 activity and enhance hepatic insulin action. However, there was no difference in hepatic AKT2 activity in the basal state, or after $20 \mathrm{~min}$ or $120 \mathrm{~min}$ of insulin stimulation (end of clamp) (Fig. 4a). Similarly, Trib3 ASO did not alter white adipose tissue AKT phosphorylation or AKT activity despite a significant knockdown of Trib3 (Fig. 4e, ESM Fig. 1c). We also assessed AKT2 activation by assessing site-specific phosphorylation. There was no difference in AKT phosphorylation on the Thr 308 residue in liver, adipose tissue and muscle after insulin stimulation, and no difference in phosphorylation of Ser 473 residue in liver and white adipose tissue (ESM Fig. 2a, b).

Interestingly, although ASOs do not directly decrease target expression in skeletal muscle, we found a trend towards reduced Trib3 expression in the soleus (40\% reduction compared with control ASO, $p=0.09$ ) (Fig. 3a). This was accompanied by a significantly higher glucose uptake in the soleus (Fig. 3b). Unlike in liver or white adipose tissue, these changes in Trib3 expression were abolished by BADGE treatment (Fig. 3a). This may be a secondary effect related to improved insulin sensitivity, as insulin itself has been shown to modulate Trib3 expression in vitro [32]. The increases in whole-body insulin-mediated glucose disposal developed without increase of insulin-stimulated AKT2 activity (Fig. 3d). Again, we confirmed the results of the AKT2 activity assay by examining AKT2 phosphorylation. In the soleus, although there were no differences in phosphorylation at Thr 308, there was a mild decrease in Ser 473 phosphorylation (ESM Fig. 2c). The increase in plasma adiponectin may also improve insulin action via activation of AMP-activated protein kinase (AMPK) [33]. Despite elevated adiponectin levels, we did not detect a significant increase in AMPK activity in soleus (Fig. 3c). 
Fig. 4 Insulin signalling and gene expression in liver. a AKT2 activity in liver tissue at times indicated. b Liver triacylglycerol and (c) diacylglycerol content. d Expression of genes important for energy homeostasis, glucose and lipid metabolism in liver. e Phosphorylation of AKT in basal white adipose tissue and after 20 min insulin stimulation. Values are given as mean $\pm \mathrm{SE}$, $n=7-9$ per group. ${ }^{*} p<0.05$, $* * p<0.01$. White bars, Trib3 ASO; grey bars, control ASO a

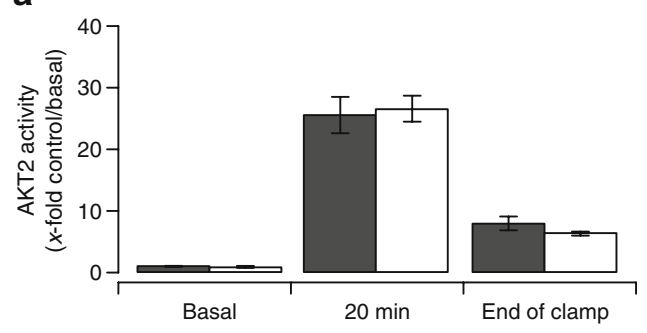

b
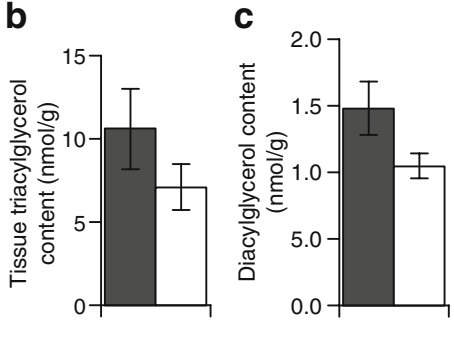

\section{d}
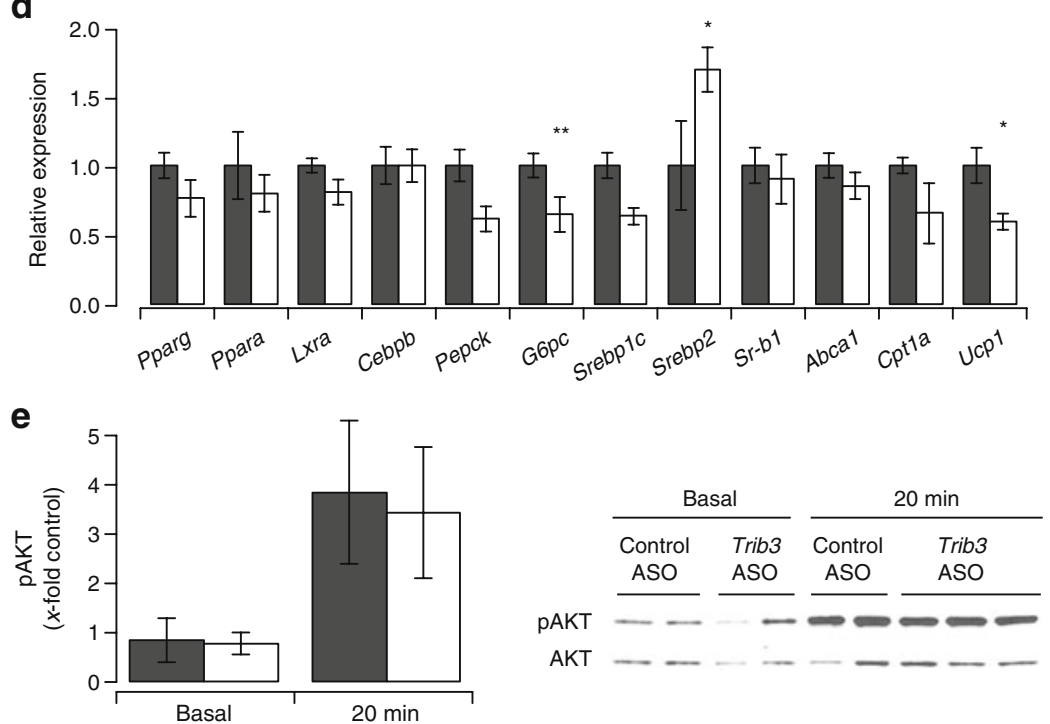

\section{Discussion}

Insulin regulates diverse metabolic pathways within the cell via intricate networks of signalling proteins. These networks converge on key focal points, one of which is activation of AKT2 [3]. Recently TRIB3, the mammalian homologue of the Drosophila tribbles, has been identified as a negative regulator of AKT2. Its abundance is increased in rodent models of type 2 diabetes mellitus, as well as with fasting. In both cases, this is associated with decreased AKT2 activation [6, 8-10, 34, 35]. In addition, production of TRIB3 itself may also be induced by insulin and may be the effector of a negative feedback loop [10,32]. In vitro studies have demonstrated that TRIB3 inhibits AKT2 in HepG2 cells and that adenoviral-mediated increases in hepatic Trib3 expression in normal mice impair glucose disposal [6]. However, genetic deletion of Trib3 in mice failed to alter glucose metabolism or AKT activation following insulin stimulation [17], casting doubt on the physiological relationship between TRIB3 and AKT. In addition, TRIB3 has been shown to partner with other proteins, notably PPAR- $\gamma$ and CEBPB [32]. We sought to understand the physiological role of TRIB3 in vivo, as a potential regulator of insulin action and glucose metabolism, using specific ASOs to knockdown Trib3 in rats.
Accordingly, we hypothesised that knockdown of Trib3 would enhance AKT2 activation and improve hepatic insulin sensitivity in a rat model of insulin resistance.

Although ASO treatment effectively and selectively reduced hepatic Trib3 expression by $70 \%$, there was, surprisingly, no effect on basal and insulin-mediated activation of AKT2 in the liver, either at 20 min following insulin stimulation or at the end of a 120 min euglycaemichyperinsulinaemic clamp. Consistent with this, no difference was observed in hepatic insulin sensitivity. In white adipose tissue, Trib3 expression was similarly decreased, but, again, no differences were observed in glucose uptake or in the degree of AKT phosphorylation in the basal state or after insulin stimulation (Fig. 4e). Furthermore, analysis of the phosphorylation state of the Thr 308 residue, which is essential for AKT activation [36], and of the Ser 473 residue, which is required for maximal stimulation of AKT, revealed no difference in liver and white adipose tissue. Consistent with this observation, AKT2 activation was not altered in $\mathrm{Trib3}^{-/-}$mice studied under normal chow conditions [17]. Thus, while it remains possible that Trib3 overexpression may inhibit AKT2 activation, the inverse may not be true. Specifically, inhibition of TRIB3 does not enhance AKT2 activity. Instead, we propose, that the improvements in insulin action following knockdown of 
Trib3 are primarily a function of augmented PPAR- $\gamma$ activity in the adipose tissues.

The transcriptional control of adipogenesis requires careful orchestration of multiple regulatory proteins. Early adipogenesis is characterised by increased abundance of CEBPB and CEBPD. These proteins are thought to set the stage for the later stages of adipogenesis, which require the increased levels of CEBPA and PPAR- $\gamma$ [37]. These proteins increase each other's production and bind to a remarkably similar number of target genes [38]. Previous in vitro studies in 3T3-L1 pre-adipocytes demonstrated a role for TRIB3 in adipogenesis [19, 39]. Overproduction of TRIB3 in 3T3-L1 cells may impair the early steps of adipogenesis. Here, TRIB3 is thought to inhibit CEBPB transcription by preventing its phosphorylation by extracellular signal-regulated kinases 1 and 2, as well as by directly interfering with its ability to bind DNA. This, in turn, inhibits its ability to increase production of PPAR- $\gamma 2$. Takahashi et al. explored the role of TRIB3 late in the differentiation of 3T3-L1 cells [19]. They report that TRIB3 directly binds to and inhibits PPAR $-\gamma$ in $3 \mathrm{~T} 3-\mathrm{L} 1$ preadipocytes, leading to decreased production of PPAR- $\gamma$ and CEBPA, and key target genes, and ultimately impairing adipocyte differentiation. In those studies, CEBPB production was not altered at any time point. Thus, it is possible that TRIB3 may have different inhibitory roles throughout adipogenesis. In the early stages, it may impair CEBPB activity and in the later stages PPAR- $\gamma$.

In the present study we found that ASO-mediated decrease of Trib3 augmented PPAR- $\gamma$ activity in vivo, leading to improvements in insulin sensitivity, increased fat mass and increased expression of genes downstream of PPAR- $\gamma$ such as Acoxl, Cd36 and Cebpa. We found that increased PPAR- $\gamma$ activity was associated with increased Pparg expression. It is likely that this represents a feedforward activation of PPAR- $\gamma$ by itself, which has previously been shown to be dependent on increased levels of CEBPA [40]. Although insulin-stimulated white adipose tissue 2-deoxyglucose uptake was not increased, there was a modest but significantly greater suppression of NEFA after insulin stimulation, which suggests an improved adipocyte insulin response (Table 1) [41]. Additionally, plasma adiponectin levels were modestly increased with Trib3 ASO. Adiponectin has been reported to improve muscle insulin sensitivity via an AMPKmediated mechanism [42]. However, in the present study, there were no significant increases in skeletal muscle AMPK activity.

To determine whether the increases in adiposity and improvements in insulin action were due to activation of PPAR- $\gamma$, we treated a separate cohort of Trib3 ASO-treated rats with the PPAR- $\gamma$ antagonist BADGE. BADGE is a PPAR- $\gamma$ ligand that antagonises PPAR- $\gamma$ activation without affecting PPAR- $\alpha$ or PPAR- $\delta$ activation [43]. The combination of Trib3 ASO and BADGE prevented the expansion of fat mass, the increased production of PPAR- $\gamma$ and its target genes, Acoxl, Cd36 and Cebpa, and the increase in plasma adiponectin. Importantly, BADGE also prevented the improvements in insulin sensitivity with Trib3 ASO treatment. These data suggest that the improvements in insulin action observed with Trib3 knockdown are largely attributable to activation of PPAR- $\gamma$.

In addition to the changes in insulin sensitivity, we also found that Trib3 ASO treatment increased the plasma HDLcholesterol concentration. This was not affected by BADGE co-treatment, suggesting that it was independent of the activation of PPAR- $\gamma$. The mechanism for this increase is unclear. We excluded altered levels of $S r-b 1$ and Abcal as explanations for the increase in HDL. It is possible that Trib3 ASO leads to increased reverse cholesterol transport though additional studies are required to confirm this. Nonetheless, these favourable changes in lipids persisted with BADGE co-treatment, suggesting that TRIB3 regulates HDL in a manner independent of PPAR- $\gamma$.

In summary, these studies provide novel insights into the physiological role of TRIB3 in vivo and its potential as a therapeutic target. Knockdown of Trib3 clearly improved insulin-stimulated peripheral glucose disposal in insulinresistant rats. However, these improvements occurred without increased activation of AKT2. Instead, these improvements in insulin sensitivity are largely attributable to activation of PPAR- $\gamma$ with resultant changes in adipogenesis. Additionally, Trib3 ASO increased plasma HDLcholesterol, independently of PPAR- $\gamma$ activation. The improvements in insulin action and lipid profile suggest that TRIB3 may be a potential therapeutic target for treating not only the insulin resistance, but also the dyslipidaemia associated with type 2 diabetes mellitus.

Acknowledgements We thank J. Dong for expert technical assistance with the studies. We also thank A. Groszmann for performing the hormone assays. This work was supported by grants from the US Public Health Service (R01 DK-40936 and P30 DK-45735 to G. I. Shulman and UL1-RR024139 to V. T. Samuel), V. A. Merit Review Award to V. T. Samuel, and from the Deutsche Forschungsgemeinschaft (DFG WE 4293/1-1 to D. Weismann).

Duality of interest X. X. Yu, S. F. Murray, S. Bhanot and B. P. Monia own stock and/or hold stock options in Isis Pharmaceuticals. All other authors declare that there is no duality of interest associated with this manuscript.

\section{References}

1. Shulman GI (2000) Cellular mechanisms of insulin resistance. J Clin Invest 106:171-176 
2. Okada T, Kawano Y, Sakakibara T, Hazeki O, Ui M (1994) Essential role of phosphatidylinositol 3-kinase in insulininduced glucose transport and antilipolysis in rat adipocytes. Studies with a selective inhibitor wortmannin. J Biol Chem 269:3568-3573

3. Taniguchi CM, Emanuelli B, Kahn CR (2006) Critical nodes in signalling pathways: insights into insulin action. Nat Rev Mol Cell Biol 7:85-96

4. Samuel VT, Liu ZX, Wang A et al (2007) Inhibition of protein kinase Cepsilon prevents hepatic insulin resistance in nonalcoholic fatty liver disease. J Clin Invest 117:739-745

5. Morino K, Petersen KF, Shulman GI (2006) Molecular mechanisms of insulin resistance in humans and their potential links with mitochondrial dysfunction. Diabetes 55(Suppl 2): S9-S15

6. Du K, Herzig S, Kulkarni RN, Montminy M (2003) TRB3: a tribbles homolog that inhibits Akt/PKB activation by insulin in liver. Science 300:1574-1577

7. Matsushima R, Harada N, Webster NJ, Tsutsumi YM, Nakaya Y (2006) Effect of TRB3 on insulin and nutrient-stimulated hepatic p70 S6 kinase activity. J Biol Chem 281:29719-29729

8. Bi XP, Tan HW, Xing SS et al (2008) Overexpression of TRB3 gene in adipose tissue of rats with high fructose-induced metabolic syndrome. Endocr J 55:747-752

9. He L, Simmen FA, Mehendale HM, Ronis MJ, Badger TM (2006) Chronic ethanol intake impairs insulin signaling in rats by disrupting Akt association with the cell membrane. Role of TRB3 in inhibition of Akt/protein kinase B activation. J Biol Chem 281:11126-11134

10. Ding J, Kato S, Du K (2008) PI3K activates negative and positive signals to regulate TRB3 expression in hepatic cells. Exp Cell Res 314:1566-1574

11. Liu J, Wu X, Franklin JL et al (2010) Mammalian tribbles homolog 3 impairs insulin action in skeletal muscle: role in glucose-induced insulin resistance. Am J Physiol Endocrinol Metab 298:E565-E576

12. Prudente S, Hribal ML, Flex E et al (2005) The functional Q84R polymorphism of mammalian Tribbles homolog TRB3 is associated with insulin resistance and related cardiovascular risk in Caucasians from Italy. Diabetes 54:2807-2811

13. Shi Z, Liu J, Guo Q et al (2009) Association of TRB3 gene Q84R polymorphism with type 2 diabetes mellitus in Chinese population. Endocrine 35:414-419

14. Prudente S, Scarpelli D, Chandalia M et al (2009) The TRIB3 Q84R polymorphism and risk of early-onset type 2 diabetes. J Clin Endocrinol Metab 94:190-196

15. Andreozzi F, Formoso G, Prudente S et al (2008) TRIB3 R84 variant is associated with impaired insulin-mediated nitric oxide production in human endothelial cells. Arterioscler Thromb Vasc Biol 28:1355-1360

16. Iynedjian PB (2005) Lack of evidence for a role of TRB3/NIPK as an inhibitor of PKB-mediated insulin signalling in primary hepatocytes. Biochem J 386:113-118

17. Okamoto H, Latres E, Liu R et al (2007) Genetic deletion of Trb3, the mammalian Drosophila tribbles homolog, displays normal hepatic insulin signaling and glucose homeostasis. Diabetes $56: 1350-1356$

18. Liew CW, Bochenski J, Kawamori D et al (2010) The pseudokinase tribbles homolog 3 interacts with ATF4 to negatively regulate insulin exocytosis in human and mouse beta cells. J Clin Invest 120:2876-2888

19. Takahashi Y, Ohoka N, Hayashi H, Sato R (2008) TRB3 suppresses adipocyte differentiation by negatively regulating PPARgamma transcriptional activity. J Lipid Res 49:880-892

20. Samuel VT, Beddow SA, Iwasaki T et al (2009) Fasting hyperglycemia is not associated with increased expression of
PEPCK or G6Pc in patients with type 2 diabetes. Proc Natl Acad Sci U S A 106:12121-12126

21. Erion DM, Ignatova ID, Yonemitsu S et al (2009) Prevention of hepatic steatosis and hepatic insulin resistance by knockdown of cAMP response element-binding protein. Cell Metab 10:499-506

22. Watts LM, Manchem VP, Leedom TA et al (2005) Reduction of hepatic and adipose tissue glucocorticoid receptor expression with antisense oligonucleotides improves hyperglycemia and hyperlipidemia in diabetic rodents without causing systemic glucocorticoid antagonism. Diabetes 54:1846-1853

23. Graham MJ, Crooke ST, Monteith DK et al (1998) In vivo distribution and metabolism of a phosphorothioate oligonucleotide within rat liver after intravenous administration. J Pharmacol Exp Ther 286:447-458

24. McKay RA, Miraglia LJ, Cummins LL, Owens SR, Sasmor H, Dean NM (1999) Characterization of a potent and specific class of antisense oligonucleotide inhibitor of human protein kinase C-alpha expression. J Biol Chem 274:1715-1722

25. Neschen S, Morino K, Rossbacher JC et al (2006) Fish oil regulates adiponectin secretion by a peroxisome proliferatoractivated receptor-gamma-dependent mechanism in mice. Diabetes 55:924-928

26. Savage DB, Choi CS, Samuel VT et al (2006) Reversal of dietinduced hepatic steatosis and hepatic insulin resistance by antisense oligonucleotide inhibitors of acetyl-CoA carboxylases 1 and 2. $\mathrm{J}$ Clin Invest 116:817-824

27. Hundal RS, Petersen KF, Mayerson AB et al (2002) Mechanism by which high-dose aspirin improves glucose metabolism in type 2 diabetes. J Clin Invest 109:1321-1326

28. Neschen S, Moore I, Regittnig W et al (2002) Contrasting effects of fish oil and safflower oil on hepatic peroxisomal and tissue lipid content. Am J Physiol Endocrinol Metab 282: E395-E401

29. Bligh EG, Dyer WJ (1959) A rapid method of total lipid extraction and purification. Can J Biochem Physiol 37:911917

30. Pfaffl MW (2001) A new mathematical model for relative quantification in real-time RT-PCR. Nucleic Acids Res 29:e45

31. R Development Core Team (2005) R: A language and environment for statistical computing. R Foundation for Statistical Computing, Vienna. ISBN 3-900051-07-0. Available from www. R-project.org

32. Du K, Ding J (2009) Insulin regulates TRB3 and other stressresponsive gene expression through induction of C/EBPbeta. Mol Endocrinol 23:475-485

33. Civitarese AE, Ukropcova B, Carling S et al (2006) Role of adiponectin in human skeletal muscle bioenergetics. Cell Metab 4:75-87

34. Cheng KK, Iglesias MA, Lam KS et al (2009) APPL1 potentiates insulin-mediated inhibition of hepatic glucose production and alleviates diabetes via Akt activation in mice. Cell Metab 9: $417-427$

35. Kato S, Du K (2007) TRB3 modulates C2C12 differentiation by interfering with Akt activation. Biochem Biophys Res Commun 353:933-938

36. Chen R, Kim O, Yang $J$ et al (2001) Regulation of Akt/PKB activation by tyrosine phosphorylation. J Biol Chem 276:3185831862

37. Rosen ED (2005) The transcriptional basis of adipocyte development. Prostaglandins, Leukot Essent Fatty Acids 73:31-34

38. Lefterova MI, Zhang Y, Steger DJ et al (2008) PPAR $\hat{I}^{3}$ and C/EBP factors orchestrate adipocyte biology via adjacent binding on a genome-wide scale. Genes \& Development 22:2941-2952 
39. Bezy O, Vernochet C, Gesta S, Farmer SR, Kahn CR (2007) TRB3 blocks adipocyte differentiation through the inhibition of C/EBPbeta transcriptional activity. Mol Cell Biol 27:68186831

40. Tontonoz P, Spiegelman BM (2008) Fat and beyond: the diverse biology of PPAR $\gamma$. Annu Rev Biochem 77:289-312

41. Bajaj M, Suraamornkul S, Romanelli A et al (2005) Effect of a sustained reduction in plasma free fatty acid concentration on intramuscular long-chain fatty Acyl-CoAs and insulin action in type 2 diabetic patients. Diabetes 54:3148-3153

42. Bergeron R, Russell RR 3rd, Young LH et al (1999) Effect of AMPK activation on muscle glucose metabolism in conscious rats. Am J Physiol 276:E938-E944

43. Wright HM, Clish CB, Mikami T et al (2000) A synthetic antagonist for the peroxisome proliferator-activated receptor $\gamma$ inhibits adipocyte differentiation. J Biol Chem 275:1873-1877 